3 Sølver, C. V. (1946). Leiðarsteinn: the compass of the Vikings. Old-Lore Miscellany, 10, 293.

4 Chaucer, G. Treatise on the Astrolabe (1391).

5 Neckham, A. De Naturis Rerum, Chap. XCVIII (I 187 ?).

6 Berachya (1 $2^{\text {th }}$ or $13^{\text {th }}$ century). On Stones. Quoted by A. Schück (1911) in Die Vorgänger des Kompasses.

7 Nicolas, Sir H. H. (1 847). A History of the Royal Navy. More, A. (1 914 ). Accounts and inventories of John Starlyng. Mariner's Mirror, 4, 22.

8 Motzo, Bacchiso R. (1947). Il Compasso da Navigare, Cagliari-Universita. Taylor, E. G. R. (195I). The oldest Mediterranean pilot. This Journal, 4, $8 \mathrm{I}$.

9 Taylor, E. G. R. (195I). Early charts and the origin of the compass rose. This Journal, 4,351 .

\title{
Low-Altitude Astro Sights
}

\author{
from P. L. Nightingale
}

ON $\mathrm{I}_{3}$ flights at different heights and outside air temperatures a total of 127 low-altitude sights were taken of the Sun, Moon and planets. The sights were taken with a Kollsman periscopic sextant which uses an illuminated graticule as a datum. Hughes' Tables were used for the calculations and the corrections for refraction taken from the table published in Navigation. ${ }^{1}$

General Observations. The sights proved to be as accurate as higher altitude sights, as the mean error of the total was $4.5 \mathrm{n} . \mathrm{m}$. and 93.7 per cent of the total were within $1 \circ \mathrm{n.m}$. of the actual position (ground positions or good track and groundspeed checks).

The sights are spread fairly evenly over the band of altitudes from $9^{\circ}$ to below zero (see Fig. I.). The 33 sights below $\mathrm{x}^{\circ}$ have a mean error of $5^{\circ} \mathrm{n} \mathrm{n} . \mathrm{m}$. but if one sight of error $20 \mathrm{n} . \mathrm{m}$. is omitted the average error becomes $4.5 \mathrm{n} . \mathrm{m}$., i.e. the same as the mean error for the 127 sights.

The distribution of sights between high and low is almost even with 62 low and 59 high with 6 zero error. The residual error is only 0.42 n.m. high (no allowance has been made for personal error as it apparently is a very variable factor ${ }^{2}$ ). It is interesting to note that while the 62 low sights are all within Io n.m., 8 of the high sights exceed Io n.m. in error; the errors being I I, I I, I I , I I $\frac{1}{2}, I_{2} \frac{1}{2}, 14,17$ and 20 n.m. respectively.

Accuracy and Use. The majority of the sights were taken when the body was almost dead ahead or astern of the aircraft, so that a good idea of their usefulness in checking groundspeed was obtained. It has always been the author's practice to average two, or at times three, successive sights of the Sun when checking groundspeed with Sun sights. This method was therefore adopted and the results tabulated to check the percentage gain in accuracy by combining two or more sights.

The average of two sights gives a good increase in accuracy and reduces the maximum error quite considerably. The inclusion of the third sight only increases the percentage of the position lines below $5 \mathrm{n} . \mathrm{m}$. although the mean error for I I averaged sights is now only $2 \cdot 7$ n.m.

One fact which came to light when tabulating the errors was the relationship of the distance between successive position lines and the accuracy of the mean 

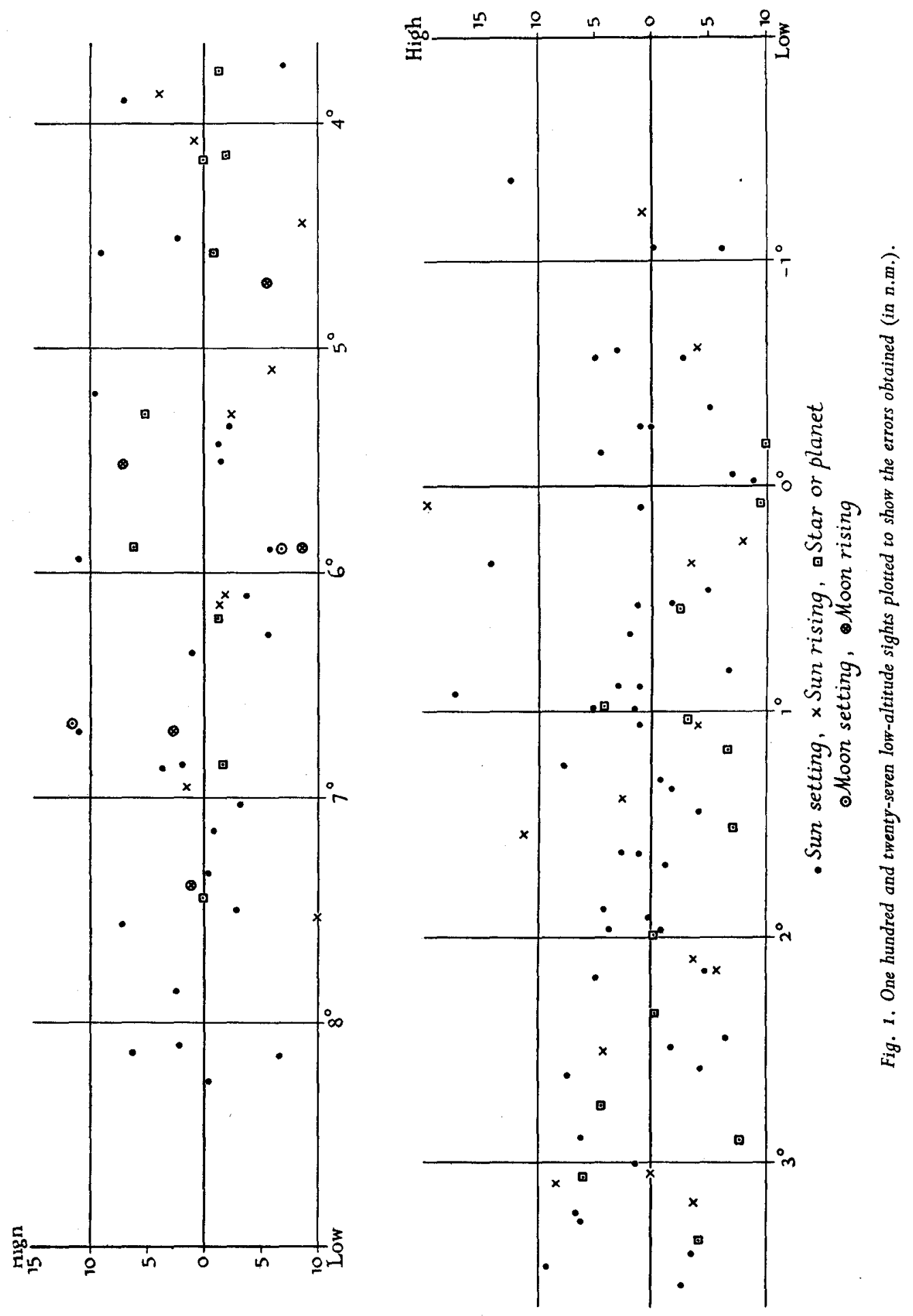
position line obtained from them. The fact that two position lines were separated by as much as $28 \mathrm{n} . \mathrm{m}$. did not indicate that one was far less accurate than the other, but rather that one sight was high and the other low. In Table II all pairs of sights (a total of I 4) separated by more than ro n.m. have been tabulated and an equal number of pairs of sights have been selected of less than 10 n.m. separation to indicate this point.

TABLE I

\begin{tabular}{|c|c|c|c|c|c|c|c|}
\hline \multirow{2}{*}{$\begin{array}{l}\text { No. of sights } \\
\text { averaged }\end{array}$} & \multirow{2}{*}{$\begin{array}{c}\text { No. of P.L.s } \\
\text { obtained }\end{array}$} & \multicolumn{4}{|c|}{ Percentage within } & \multirow{2}{*}{$\begin{array}{l}\text { Max. } \\
\text { error }\end{array}$} & \multirow{2}{*}{$\begin{array}{l}\text { Mean } \\
\text { error }\end{array}$} \\
\hline & & $2 \frac{1}{2} \mathrm{n} . \mathrm{m}$ & $5 \mathrm{n} . \mathrm{m}$ & $7 \frac{1}{2}$ n.m. & I o n.m. & & \\
\hline $\mathbf{I}$ & 127 & $39 \cdot 5$ & $64 \cdot 6$ & $84 \cdot I$ & $94 \cdot 0$ & 20.00 & $4 \cdot 50$ \\
\hline 2 & I I 3 & $49 \cdot 5$ & $86 \cdot 4$ & $94 \cdot 8$ & $98 \cdot 1$ & $12 \cdot 25$ & $3 \cdot 10$ \\
\hline 3 & 101 & $57 \cdot 5$ & $88 \cdot 0$ & $96 \cdot 0$ & $99 \cdot \mathrm{I}$ & 10.50 & $2 \cdot 70$ \\
\hline
\end{tabular}

TABLE II

\begin{tabular}{|c|c|c|c|c|c|c|c|}
\hline \multicolumn{4}{|c|}{ Position lines less than Io n.m. apart } & \multicolumn{4}{|c|}{ Position lines more than $10 \mathrm{n.m}$. apart } \\
\hline \multirow{2}{*}{$\begin{array}{c}\text { Distance } \\
\text { between } \\
\text { P.L.s } \\
\text { (n.m.) }\end{array}$} & \multicolumn{2}{|c|}{$\begin{array}{l}\text { Errors } \\
\text { (n.m.) }\end{array}$} & \multirow{2}{*}{$\begin{array}{c}\text { Error of } \\
\text { mean } \\
\text { P.L.s } \\
\text { (n.m.) }\end{array}$} & \multirow{2}{*}{$\begin{array}{c}\text { Distance } \\
\text { between } \\
\text { P.L.s } \\
\text { (n.m.) }\end{array}$} & \multicolumn{2}{|c|}{$\begin{array}{l}\text { Errors } \\
\text { (n.m.) }\end{array}$} & \multirow{2}{*}{$\begin{array}{c}\text { Error of } \\
\text { mean } \\
\text { P.L.s } \\
\text { (n.m.) }\end{array}$} \\
\hline & Low & High & & & Low & High & \\
\hline nil & & I I-I I & I I & $\operatorname{II} \frac{1}{2}$ & 7 & $4 \frac{1}{2}$ & $\mathbf{I} \frac{1}{4}$ \\
\hline nil & & $6-6$ & 6 & $I I \frac{1}{2}$ & I0 & $1 \frac{1}{2}$ & $4 \frac{1}{4}$ \\
\hline nil & $6-6$ & & 6 & $12 \frac{1}{2}$ & $8 \frac{1}{2}$ & 4 & $2 \frac{1}{4}$ \\
\hline$\frac{1}{2}$ & $9 \frac{1}{2}-10$ & & $9 \frac{3}{4}$ & 13 & & I 4-I & $7 \frac{1}{2}$ \\
\hline$\frac{1}{2}$ & & $9-9 \frac{1}{2}$ & $9 \frac{1}{4}$ & $13 \frac{1}{2}$ & $4 \frac{1}{2}$ & 9 & $2 \frac{1}{4}$ \\
\hline$\frac{1}{2}$ & $7 \frac{1}{2}-7$ & & $7^{\frac{1}{4}}$ & 14 & 6 & 8 & I \\
\hline$\frac{1}{2}$ & & $7-6 \frac{1}{2}$ & $6 \frac{3}{4}$ & $14 \frac{1}{2}$ & $3 \frac{1}{2}$ & 11 & $3 \frac{3}{4}$ \\
\hline$\frac{1}{2}$ & & $6 \frac{1}{2} 7$ & $6 \frac{3}{4}$ & 15 & 4 & I $\mathbf{I}$ & $3 \frac{1}{2}$ \\
\hline I $\frac{1}{2}$ & & I $1-9 \frac{1}{2}$ & $10 \frac{1}{4}$ & I $5 \frac{1}{2}$ & $8 \frac{1}{2}$ & 7 & $\frac{3}{4}$ \\
\hline 3 & & $9-6$ & $7 \frac{1}{2}$ & 17 & 6 & I I & $2 \frac{1}{2}$ \\
\hline 3 & $7-4$ & & $5 \frac{1}{2}$ & $18 \frac{1}{2}$ & 6 & $12 \frac{1}{2}$ & $3 \frac{1}{4}$ \\
\hline 4 & $8-4$ & & 6 & $18 \frac{1}{2}$ & 7 & $11 \frac{1}{2}$ & $2 \frac{1}{4}$ \\
\hline 4 & & $8-4$ & 6 & 22 & 5 & 17 & 6 \\
\hline $5 \frac{1}{2}$ & & $5-1 \mathrm{I} \frac{1}{2}$ & $8 \frac{1}{4}$ & 28 & 8 & 20 & 6 \\
\hline
\end{tabular}

\section{Mr. D. H. Sadler comments:}

Records of observations such as those obtained by Mr. Nightingale are of considerable value and interest; more observations at even lower altitudes would be welcomed. The most interesting information derivable from them is the variability of the theoretical refraction, but the present observations hardly allow this to be separated from the many other factors. In clear conditions there seems little reason why the accuracy of sighting an object should decrease 
significantly with altitude, especially when using a periscopic sextant. Thus any difference in accuracy should be attributable to the inadequacy of the refraction corrections; for the conditions above these uncertainties are clearly smaller than those from other sources.

I am surprised that Mr. Nightingale has used Willems' table for calculating the refraction; this is a crude extrapolation of a mixture of existing tables for normal conditions, and has little theoretical justification. Actually, however, the values given do not differ significantly from those in the Air Almanac for the range of heights and altitudes considered.

The distribution of errors in Table I appears consistent with the hypothesis that the errors are of a random nature. However, the evidence of Table II is most misleading: it would be quite wrong to deduce that the accuracy of the mean of two position lines differing by more than $10 \mathrm{n} . \mathrm{m}$. was greater than the mean of two differing by less than io n.m. This might conceivably be the case if the possibility of blunders could be eliminated, but the larger the separation the greater the chance of a blunder.

\section{Mr. J. B. Parker comments:}

There being no evidence to the contrary, it is usual to assume that, in the absence of any systematic errors, successive observations of a physical quantity are independent of each other. Mr. Nightingale's Table II indicates that where the distance between two successive position lines is small, systematic biases of from about 5 to i i nautical miles were present; but for spacings over ro n.m. a systematic error of over 5 n.m. was revealed on only three occasions. It appears then, that there is a tendency for the second sight either to be similar in magnitude to the first (first section of Table II) or to be of a compensating sense (second section of Table II).

This abnormal state of affairs indicates that, while all the observations taken together may be consistent with a random distribution, successive shots are by no means independent. Errors that are systematic over a short period of time are quite understandable (first section of Table II), but it is difficult to explain the results in the second section unless the observer was sometimes aware that his first sight was high, or low, and took some action (consciously or unconsciously) to compensate for this during the second shot.

It would be of interest to know whether the first series quoted in Table II were taken under similar conditions to the second series; the results would be less difficult to explain, for example, if the second series were obtained under bumpy conditions, while the first corresponded to smooth flight.

The statement that the larger the separation between two position lines, the greater is the chance that a blunder has occurred, is a straightforward consequence of what is loosely termed the 'law of errors'. This law states, inter alia, that apart from possible biases, successive observations are independent of each other, provided they are taken under similar conditions. If the law breaks down, there must be some, at present unknown, physical agency responsible for the fact. While 127 sights are not sufficient to prove this lack of independence, let alone establish its cause, the results are so intensely interesting that navigators' records of a similar nature (not necessarily confined to low-altitude shots), together with the observers' views about their distribution, would be of great value, and the Institute would like to have full particulars. 
Mr. Nightingale writes:

I agree with Mr. Sadler that Table II is misleading, for my I 4 selected pairs of sights below I $\circ$ n.m. separation are less accurate than those above I $\circ$ n.m. I did not consciously select the less accurate sights.

I give below more detailed figures on the separation of successive position lines and their errors. The total number of position lines obtained from two successive sights was i 13 .

Total less than io n.m. separation-9o.

Number with error of $5 \mathrm{n} . \mathrm{m}$. and over- 22 or $24^{\circ} 4$ per cent.

Number with error of 10 n.m. and over- 2 or 2.22 per cent.

Average error- $3 \cdot 24$ n.m.

Total of 10 n.m. and over separation-23.

Number with error of 5 n.m. and over- 4 or 17.4 per cent.

Number with error of ro n.m. and over-nil.

Average error-2.64 n.m.

These results show that in fact the successive position lines separated by ro n.m. and more (the maximum was $28 \mathrm{n} . \mathrm{m}$.) were less liable to large systematic errors by 17.4 per cent to $24 \cdot 4$ per cent and that the mean error was less, $2 \cdot 64$ n.m. against $3 \cdot 24$ n.m.

In reply to Mr. J. B. Parker, the conditions were exactly the same in both cases, in fact as far as was possible all the sights were taken under ideal conditions. No attempt was made to take sights under bumpy conditions.

\section{REFER ENCES}

1 Willems, R. C. (195I). Low altitude refraction correction. Navigation, Los Angeles, 3,41 .

2 Hagger, A. J. (1952). The accuracy of bubble sextant observation. This Journal, 5 , 380 .

\section{Priming and Lagging}

$$
\text { from E. E. Mann }
$$

The term 'Priming and Lagging' has been defined in two different ways.

The Admiralty Manual of Navigation (1922) defines it as occurring when the resultant of the solar and lunar tides arrives before or after the lunar tide would arrive. This is here called definition $A$. The Admiralty Manual of Tides (194I) defines it as occurring when the interval between successive diurnal high waters is less or more than the average $24^{\mathrm{h}} 50^{\mathrm{m}}$. This is here called definition $B$.

The two phenomena thus defined are distinct. If we take a horizontal line divided into equal parts to represent successive lunar days and for each day plot as ordinate the amount of priming upwards or lagging downwards, as calculated from definition $A$, and join the ends of the ordinates by a curve, we find that normally the tide primes during the week from springs to neaps (that is, Moon in first and third quarters) and lags normally during the week from neaps to springs (that is, Moon in second and fourth quarters). If we plot a similar diagram as calculated from definition $B$ we find that normally the tide primes 